\title{
Survival and community care use by care home residents in England: does mental health matter?
}

Keywords: mortality, community care, costs, mental health, dementia, care homes

Word count: 3, 359

\begin{abstract}
To provide evidence of mortality and community care costs of people living in care homes and investigate its association with mental health based on the Mental Health Clustering Tool (MHCT).

Methods: In an observational study, 5,782 residents living in 104 care homes were followed from 2014 to 2016. Residents were categorised into four groups using the MCHT: three with mental health conditions: "non-psychotic", "psychotic", or "organic" and one without mental health conditions: "non-clustered". Generalised estimating equations were used to explore associations between mean community care costs over 6 months per patient and the clustering of residents into the four groups. Differences in survival rates of residents were plotted using Kaplan-Meier curves and tested with logrank test and Cox-regression analysis. Community care costs were similar among residents with dementia (£431) and without mental health conditions ( $f 407)$ while costs were higher among residents with non-psychotic ( $f 762)$ and psychotic $(£ 1,724)$ mental health conditions. After adjusting for patient and care home characteristics, residents with dementia were $30 \%$ less likely to die compared with residents without mental health conditions. Similarly, residents with psychotic conditions and residents with non-psychotic conditions were $25 \%$ and $20 \%$ less likely to die, respectively, than residents without mental health conditions. The MHCT seems to provide an informative stratification of care home residents with regards to survival and community care use.
\end{abstract}




\section{Introduction}

Moving care from hospitals into the community has been the latest direction of health policy in England, with the Five Year Forward View being the spearhead of testing new ways of delivering community care (NHS England, 2014). To serve this purpose, innovative community-based services such as hospital-at-home, single point of access, community therapy service, emergency multidisciplinary units, community matrons, district nurses and community mental health teams, have been developed to treat people in the community rather than in hospitals. Therefore, community care, which currently accounts for more than $f 10$ billion yearly or $10 \%$ of the National Health Service (NHS) budget, becomes an increasingly important part of health care commissioning in England (Lafond et al., 2016).

Following the Five Year Forward View, different models of integrated care have been recently established including the Enhanced Health in Care Homes (EHCH), multispecialty community providers (MCP), and integrated primary and acute care systems (PACS) (NHS England, 2016c). EHCH initiatives work closely with MCP and PACS and aim to improve the quality of life, healthcare and health planning for people living in care homes (NHS England, 2016d). Integrating care is a crucial factor for delivering high quality care for residents in care homes because of their complex care needs due to high prevalence of cognitive impairment, multi-morbidity and polypharmacy. Approximately 416,000 people are living in care homes, which is about $4 \%$ of the population aged 65 years and over, and this figure rises to $16 \%$ for those aged 85 or more (Laig, 2014). Of all care home residents, approximately $40 \%$ have depression, which can increase with age as older people are more susceptible to risk factors leading to depression such as chronic illnesses and disability (Godfrey and Denby, 2004). Furthermore, $70 \%$ have dementia or significant memory problems while $11 \%$ of stroke patients move to care homes right after a stroke event (Godfrey and Denby, 2004; Kane and Terry, 2015; National Audit Office, 2010). Moreover, the mortality rate is four times higher in nursing home residents (who receive 24 hour care a day by care assistants) and three times higher in residential home residents (who receive 24 hour care a day by nurses) compared with their community counterparts (Shah et al., 2013). High mortality among nursing home residents and residential home residents can be partly attributed to cognitive impairment and behavioural disturbance indicative of needing mental health management (Gordon et al., 2014). Therefore, addressing the mental health care needs of care home residents is essential.

Patients with mental health problems face a lack of access to necessary physical healthcare and people with long-term physical health conditions also suffer higher rates of complications if they develop 
mental health conditions, which can increase costs of care by 45\% (Mental Health Taskforce, 2016). However, evidence shows that integrated care models and services can reduce these poor health outcomes and increased costs of care (Mental Health Taskforce, 2016). Integration of care can only be achieved if accompanied by alternative payment methods (Tsiachristas, 2015; Tsiachristas et al., 2011, 2013). Therefore, healthcare commissioners are urged to design payments for these integrated care models that include community care and adequately reflect the mental health needs of people with long-term physical health conditions (Mental Health Taskforce, 2016).

Community care costs are expected to constitute a relatively large part of payments for $\mathrm{EHCH}$ considering that these costs account for about $40 \%$ and $21 \%$ of the total costs of dementia and stroke respectively, while these proportion is only $5 \%$ and $2 \%$ in cancer and coronary heart disease (LuengoFernandez et al., 2012). The mental health components of these payments are likely to be reimbursed similar to the new payment approaches that have been developed by NHS England and NHS Improvement to support commissioning and provision of mental health care as part of the National Tariff Payment system (NHS England, 2016a, 2016b). These payment approaches are based on the stratification of mental health patients into non-psychotic, psychotic, and organic (i.e. cognitive impairment and dementia) using the Mental Health Clustering Tool (MHCT) (NHS Improvement, 2016). The MHCT was developed by the Department of Health and Social Care to support the implementation of Mental Health Payment by Results as it clusters a group of people with similar health and social care outcomes measured by the Health of the Nation Outcome Scales (HoNOS). Although the diagnostic accuracy of MHCT has been assessed (Trevithick et al., 2015), little is known about how this stratification tool is associated with mortality and community care utilisation.

Considering the use of the MHCT to design payment approaches, evidence on mortality and community care use of people living in care homes with and without mental health conditions are crucial for informing commissioning decisions, managing services, and designing payments for integrated care services. The number of UK studies investigating mortality and length of stay in care homes are limited and existing studies do not consider the mental health care needs of those living in care homes (Forder and Fernandez, 2011; Shah et al., 2013; Steventon and Roberts, 2012). Furthermore, there is currently neither national data collection for community care nor scientific studies of community care costs of people living in care homes. The closest studies to this population are costing studies focusing on dementia but they either do not include community care costs (Gustavsson et al., 2010; Murman et al., 2002; Schaller et al., 2015) or have small sample sizes (Gage et al., 2015). Therefore, the aim of this study was to provide evidence about the mortality and costs of community care of people living in care homes and explore its association with mental health based 
on the stratification of the MHCT. Such evidence is important for healthcare commissioners in England to efficiently plan and commission necessary healthcare services for elderly people in care homes.

\section{Methods}

\subsection{Study design and data}

In a two-year observational study, we explored the community care utilisation of all people living in all care homes (i.e. 104) between 1 April 2014 and 31 March 2016 in Oxfordshire, South East England. All data was routinely collected and was extracted every 6-months from electronic patient records for a period of two years. The data included individual-level usage of community care services and consisted of 5,782 care home residents with 15,418 community care utilisation records. Therefore, each resident could have up to four data points in the two-year long study period. The data included admissions to general and mental health wards in community hospitals as well as utilisation of community services (a full list of community care services is provided in Box 1 in the Appendix). Unit costs of community services were provided by local health authorities that were involved in the commissioning of these services. Patient characteristics (i.e. age and gender) and care home characteristics (i.e. number of beds and type of care home) were also available. All residents were grouped, by clinicians, into having "non-psychotic", "psychotic" or "organic" mental health conditions based on the MHCT and those who were assessed by clinicians without having any mental health condition were labelled as "non-clustered" in the dataset. The survival of each resident in the data set was calculated from admission to care home to death or end of the study follow-up, whichever came first.

\subsection{Statistical analysis}

Kruskal-Wallis tests for continuous variables and Chi-square tests for categorical variables were used to explore differences between residents grouped into non-psychotic, psychotic, organic, nonclustered, in terms of: a) resident age and gender, b) care home type (i.e. residential or nursing home) and size (measured in number of beds), c) utilisation of community care services, and d) community care costs. Differences in the survival of residents between mental health clusters were plotted using Kaplan-Meier curves and tested with the log-rank test as well as by performing a Cox-regression analysis to adjust death relative risks for differences in patient characteristics (i.e. age and gender) and care home characteristics (i.e. type and size). The standard errors in the Cox-regression allowed for intra-cluster correlation (i.e. correlation between residents of the same care home). The 
proportional-hazards assumption was tested on the basis of Schoenfeld residuals after fitting the Coxregression model.

A multilevel regression analysis using generalised estimating equations (GEE) with gamma distribution and log link was performed to investigate the association between mean community care costs over 6 months per patient (i.e. the outcome variable) and the clustering of residents into non-psychotic, psychotic, organic, non-clustered (i.e. the exposure variable). A gamma distribution was used as the outcome variable, community care costs, is a positive and skewed continuous variable. To adjust for confounding, we included variables expected to be associated with community care costs and mental health clustering such as resident age, gender, and survival as well as type and size of care home. We specifically controlled for the size of care home due to a Care Quality Commission report that showed larger care homes were more likely to take some action to ensure they met quality standards compared to small care homes (i.e. up to 100 residents) (Care Quality Commission, 2013). In all regression models, patients (level 1) were clustered in care homes (level 2) and cluster-robust standard errors were estimated.

\section{Results}

Of the 5,782 residents, 3,012 (52\%) had cognitive impairment or dementia (categorised as organic), $226(4 \%)$ had non-psychotic mental health condition, 119 (2\%) had psychotic mental health condition while, 2,425 (42\%) had no mental health condition (categorised as non-clustered) (Table 1). The majority of the residents were females (70\%) and were living in nursing homes (71\%) and there was small variation in these proportions across the mental health clusters. The mean age at the beginning of the follow-up period in the whole sample was 87 and ranged from 80 in the psychotic cluster to 88 in the non-clustered residents. The mean number of beds in the 104 care homes was 52 with a small variation between the four mental health groups of residents. As shown in the bar charts of Figure 1, the distribution of residents with mental health conditions was similar across the 104 care homes.

During six months, residents in care homes contacted district nurses on average 3.35 (SD: 11.66) times, out-of-hours services 0.54 times (SD: 0.85 ), community mental health teams 0.28 times (SD: 1.21), a podiatrist 0.26 times (SD: 1.44), and speech and language therapists 0.22 times (SD: 0.79) (Table 2). Comparing community care utilisation across the four mental health categories, residents with nonpsychotic disorders contacted emergency multidisciplinary units and hospital-at-home services slightly more frequently compared to residents in the other three categories. Together with residents with psychotic conditions, residents with non-psychotic conditions contacted community mental health teams most frequently while residents with dementia contacted community mental health 
teams less often. Residents with psychotic and non-psychotic conditions contacted community mental health teams on average of 1.57 times (SD: 3.28 ) and 1.38 times (SD: 3.06$)$, respectively. Residents with dementia contacted community mental health teams on average of 0.35 times (SD:1.16). Residents with psychotic conditions were by far the group with the most frequent admissions to mental health wards in community hospitals (mean: 2.44, SD: 15.04). Residents with dementia visited community therapy services (mean: $0.70, \mathrm{SD}: 0.52$ ) and memory clinics (mean: $0.06, \mathrm{SD}: 0.24$ ) slightly more often compared to all other residents. On average, residents without mental health conditions contacted out-of-office hours services 0.62 times (SD: 0.97) in 6 months, which is slightly more frequently compared with residents with mental health conditions.

The mean 6-month community care costs per resident were $f 460$ (SD: $£ 1,879$ ) and were driven primarily by the costs of district nurses (mean: $£ 139, \mathrm{SD}$ : $£ 482$ ), followed by hospitalisation in mental health wards (mean: $f 67, S D: f 1,580$ ), community mental health teams (mean: $f 54, S D$ : $f 232$ ), hospitalisation in community hospitals (mean: f52, SD: f640), and out-of-office hour services (mean: f41, SD: f71) (Table 2). The community care costs of residents with dementia and residents without mental health conditions heavily influenced the mean community care costs of the whole sample (because they constituted $94 \%$ of the study sample). However, these costs were higher among residents with non-psychotic $(£ 762)$ and psychotic $(£ 1,724)$ mental health conditions and the main cost drivers were community mental health services and hospitalisation in metal health wards, respectively. 
Table 1. Patient characteristics and resource utilisation of care home residents

\begin{tabular}{|c|c|c|c|c|c|c|}
\hline \multicolumn{7}{|c|}{ Panel A: Patient and care home characteristics } \\
\hline & & Total sample & Non-psychotic & Psychotic & Organic & Non-clustered \\
\hline Sample size & & $5,782(100 \%)$ & $226(4 \%$ of 5,782$)$ & $119(2 \%$ of 5,782$)$ & $3,012(52 \%$ of 5,782$)$ & $2,425(42 \%$ of 5,782$)$ \\
\hline \multirow[t]{2}{*}{ Sex } & Females & $4,040(70 \%$ of 5,782$)$ & $166(73 \%$ of 226$)$ & 85 (71\% of 119$)$ & $2,103(70 \%$ of 3,012$)$ & $1,686(70 \%$ of 2,425$)$ \\
\hline & Males & $1,742(30 \%$ of 5,782$)$ & $60(27 \%$ of 226$)$ & $34(29 \%$ of 119$)$ & $909(30 \%$ of 3,012$)$ & $739(30 \%$ of 2,425$)$ \\
\hline \multirow[t]{2}{*}{ Type of care home } & Residential & $1,649(29 \%$ of 5,739$)$ & $93(41 \%$ of 225$)$ & $32(27 \%$ of 117$)$ & $847(28 \%$ of 2,995$)$ & $677(28 \%$ of 2,402$)$ \\
\hline & Nursing & $4,090(71 \%$ of 5,739$)$ & $132(59 \%$ of 225$)$ & $85(73 \%$ of 117$)$ & $2,148(72 \%$ of 2,995$)$ & $1,725(72 \%$ of 2,402$)$ \\
\hline \multirow{2}{*}{\multicolumn{2}{|c|}{ Age at beginning of follow-up*** }} & Mean (SD) $[$ Min-Max] $\{n\}$ & Mean (SD) [Min-Max] $\{n\}$ & Mean (SD) [Min-Max] \{n\} & Mean (SD) $[$ Min-Max] $\{n\}$ & Mean (SD) [Min-Max] \{n\} \\
\hline & & $87(8)[43-110]\{5,782\}$ & $85(8)[61-103]\{226\}$ & $80(11)[47-103]\{119\}$ & $87(8)[49-110]\{3,012\}$ & $88(8)[43-107]\{2,425\}$ \\
\hline \multicolumn{2}{|c|}{ Number of beds in care home } & $52(19)[5-103]\{5,739\}$ & $49(17)[7-103]\{225\}$ & $54(23)[11-103]\{117\}$ & $53(19)[5-103]\{2,995\}$ & $52(19)[5-103]\{2,402\}$ \\
\hline
\end{tabular}

SD: standard deviation; ${ }^{* * *}$ Statistically significant difference $p$-value $<0.001$ based on Kruskal-Wallis (for continuous variables) or Chi-square (for categorical variables) test.

Figure 1. Absolute and relative numbers of residents in each mental health cluster by care home (in descending order of size)
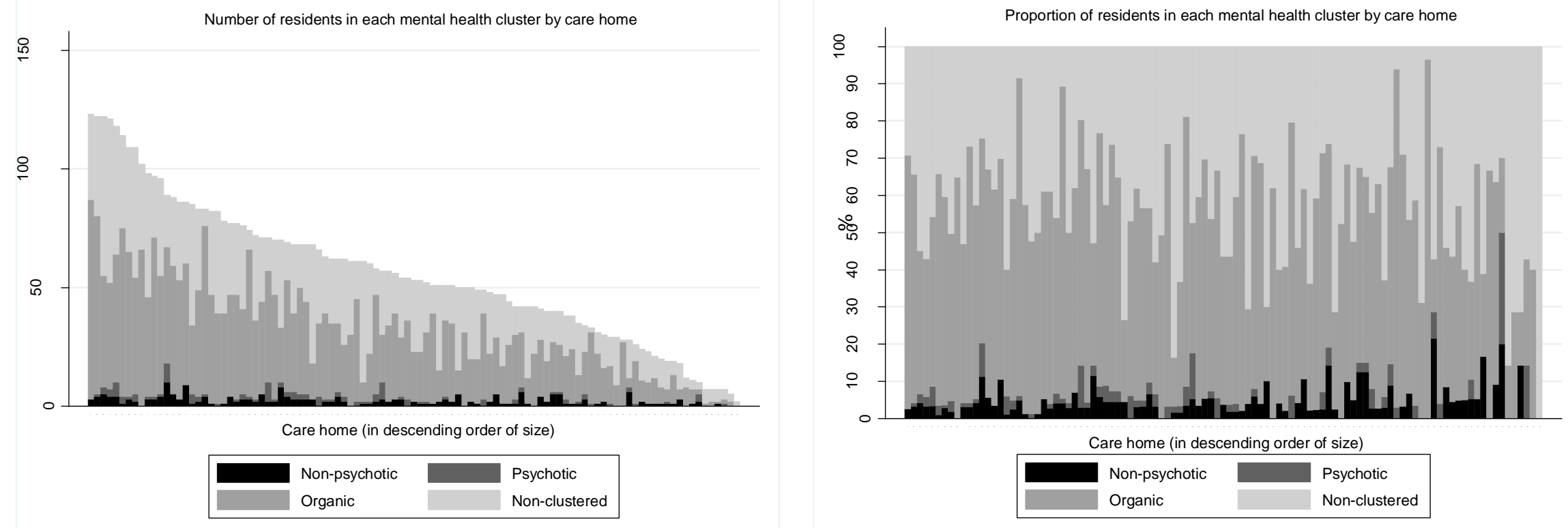
Table 2 Six-month community care utilisation and costs per resident

\begin{tabular}{|c|c|c|c|c|c|}
\hline Variable & $\begin{array}{r}\text { Total sample } \\
(5,782) \\
\text { Mean (SD) [Max] } \\
\end{array}$ & $\begin{array}{r}\begin{array}{r}\text { Non-psychotic } \\
\text { (n=226) }\end{array} \\
\text { Mean (SD) [Max] }\end{array}$ & Mean (SD) [Max] & $\begin{array}{l}\text { Organic }(\mathbf{n}=\mathbf{3}, \mathbf{0 1 2}) \\
\text { Mean (SD) }[\mathrm{Max}]\end{array}$ & $\begin{array}{r}\text { Non-clustered } \\
(\mathbf{n}=\mathbf{2 , 4 2 5}) \\
\text { Mean (SD) [Max] }\end{array}$ \\
\hline \multicolumn{6}{|c|}{ 6-month community care utilisation per resident } \\
\hline $\begin{array}{l}\text { Length of stay in community } \\
\text { hospitals (days) }\end{array}$ & $0.17(2.01)[76]$ & $0.20(1.76)[24]$ & $0.16(1.45)[16]$ & $0.11(1.66)[76]$ & $0.23(2.42)[70]$ \\
\hline $\begin{array}{l}\text { Length of stay in mental } \\
\text { health wards (days)*** }\end{array}$ & $0.15(3.52)[147]$ & $0.31(2.85)[33]$ & $2.44(15.04)[146]$ & $0.17(3.75)[147]$ & $0.00(0.00)[0]$ \\
\hline Community matron (visits) & $0.00(0.08)[3]$ & $0.00(0.07)[1]$ & $0.00(0.00)[0]$ & $0.00(0.09)[3]$ & $0.00(0.06)[2]$ \\
\hline $\begin{array}{l}\text { Community therapy service } \\
\text { (visits)*** }\end{array}$ & $0.13(0.87)[23]$ & $0.15(0.65)[5]$ & $0.13(0.99)[9]$ & $0.70(0.52)[11]$ & $0.20(1.17)[23]$ \\
\hline District nurse (visits) & $3.35(11.66)[291]$ & $2.73(6.81)[50]$ & $3.59(14.22)[141]$ & $3.20(11.31)[186]$ & $3.59(12.29)$ [291] \\
\hline $\begin{array}{l}\text { Emergency multidisciplinary } \\
\text { unit (visits)*** }\end{array}$ & $0.04(0.30)[8]$ & $0.09(0.40)[4]$ & $0.02(0.15)[2]$ & $0.03(0.25)[5]$ & $0.05(0.36)[8]$ \\
\hline Hospital at home (visits)*** & $0.04(0.30)[7]$ & $0.11(0.64)[7]$ & $0.01(0.09)[1]$ & $0.03(0.29)[7]$ & $0.04(0.27)[5]$ \\
\hline Minor injury unit (visits) $* * *$ & $0.01(0.05)[1]$ & $0.00(0.00)[0]$ & $0.01(0.06)[1]$ & $0.01(0.06)[1]$ & $0.00(0.03)[1]$ \\
\hline $\begin{array}{l}\text { Musculoskeletal service } \\
\text { (visits) }\end{array}$ & $0.00(0.05)[2]$ & $0.00(0.05)[1]$ & $0.00(0.00)[0]$ & $0.00(0.05)[2]$ & $0.00(0.03)[1]$ \\
\hline Dietician (visits) & $0.07(0.67)[20]$ & $0.14(1.49)[20]$ & $0.09(0.66)[7]$ & $0.04(0.37)[9]$ & $0.10(0.83)[20]$ \\
\hline Out-of-hours (visits)*** & $0.54(0.85)[12]$ & $0.50(0.78)[5]$ & $0.48(0.71)[3]$ & $0.49(0.74)[9]$ & $0.62(0.97)[12]$ \\
\hline Memory clinic (visits)*** & $0.03(0.18)[4]$ & $0.03(0.20)[2]$ & $0.03(0.17)[1]$ & $0.06(0.24)[4]$ & $0.00(0.06)[1]$ \\
\hline $\begin{array}{l}\text { Community mental health } \\
\text { team (visits)*** }\end{array}$ & $0.28(1.21)[25]$ & $1.38(3.06)[24]$ & $1.57(3.28)[25]$ & $0.35(1.16)[20]$ & $0.04(0.41)[17]$ \\
\hline $\begin{array}{l}\text { Physical physiotherapy } \\
\text { disability service (visits) }\end{array}$ & $0.01(0.15)[6]$ & $0.01(0.07)[1]$ & $0.00(0.05)[1]$ & $0.01(0.10)[4]$ & $0.01(0.20)[6]$ \\
\hline Podiatrist (visits) & $0.26(1.44)[23]$ & $0.44(1.73)[14]$ & 0.19 (1.02) [9] & $0.23(1.36)[23]$ & $0.29(1.52)[22]$ \\
\hline Single point of access (visits) & $0.03(0.14)[2]$ & 0.17) [2] & $0.03(0.16)[1]$ & $0.02(0.12)[1]$ & $0.04(0.16)[2]$ \\
\hline $\begin{array}{l}\text { Speech and language therapy } \\
\text { (visits) }\end{array}$ & $0.22(0.79)[19]$ & $0.14(0.52)[5]$ & $0.20(0.73)[6]$ & $0.20(0.66)[9]$ & $0.25(0.95)[19]$ \\
\hline Tissue viability (visits) & $0.06(0.32)[9]$ & $0.05(0.24)[2]$ & $0.06(0.28)[2]$ & $0.05(0.27)[6]$ & $0.07(0.38)[9]$ \\
\hline \multicolumn{6}{|c|}{ 6-month community care costs per resident, $f$} \\
\hline $\begin{array}{l}\text { Hospitalisation in community } \\
\text { hospitals }\end{array}$ & $52(640)[24,137]$ & $64(559)[7,622]$ & $50(460)[4,923]$ & $34(526)[24,137]$ & $74(769)[22,231]$ \\
\hline $\begin{array}{l}\text { Hospitalisation in mental } \\
\text { health wards*** }\end{array}$ & $\begin{array}{r}67(1,580) \\
{[65,994]}\end{array}$ & $\begin{array}{r}138(1,280) \\
{[14,703]}\end{array}$ & $\begin{array}{r}1,096(6,753) \\
{[65,545]}\end{array}$ & $\begin{array}{r}74(1,685) \\
{[65,994]}\end{array}$ & $0(0)[0]$ \\
\hline Community matron & $1(10)[397]$ & 1 (9) [133] & $0(0)[0]$ & $1(12)[397]$ & $0.4(8)[265]$ \\
\hline $\begin{array}{l}\text { Community therapy } \\
\text { service*** }\end{array}$ & $34(229)[6,058]$ & $38(172)[1,317]$ & $35(260)[2,370]$ & $18(138)[2,897]$ & $53(307)[6,058]$ \\
\hline District nurse & $\begin{array}{r}139(482) \\
{[12,035]}\end{array}$ & $113(282)[2,066]$ & $148(588)[5,837]$ & $132(467)[7,665]$ & $\begin{array}{r}148(508) \\
{[12,035]}\end{array}$ \\
\hline $\begin{array}{l}\text { Emergency multidisciplinary } \\
\text { unit*** }\end{array}$ & $14(111)[2,895]$ & $33(148)[1,447]$ & 7 (55) [543] & $12(90)[1,809]$ & $17(131)[2,895]$ \\
\hline Hospital at home*** & $6(48)[1,120]$ & $18(102)[1,120]$ & $1(15)[160]$ & $5(46)[1,120]$ & $5(44)[800]$ \\
\hline Minor injury unit *** & $0.3(3)[80]$ & $0(0)[0]$ & $1(3)[30]$ & $1(4)[80]$ & $0.2(2)[60]$ \\
\hline Musculoskeletal service & $0.1(3)[122]$ & $0.2(3)[42]$ & $0(0)[0]$ & $0.1(3)[122]$ & $0.1(2)[75]$ \\
\hline Dietician & $6(58)[1,750]$ & $12(128)[1,728]$ & $8(57)[562]$ & $3(32)[778]$ & $8(71)[1,750]$ \\
\hline Out-of-hours** & $46(71)[1,006]$ & $42(65)$ [419] & $40(59)[252]$ & $41(62)[776]$ & $52(81)[1,006]$ \\
\hline Memory clinic $* * *$ & $7(37)[813]$ & $5(41)$ [407] & 7 (34) [203] & $12(48)[813]$ & 1 (12) [203] \\
\hline $\begin{array}{l}\text { Community mental health } \\
\text { team*** }\end{array}$ & $54(232)[4,782]$ & $263(586)[4,638]$ & $300(627)[4,782]$ & $67(222)[3,825]$ & $7(79)[3,156]$ \\
\hline $\begin{array}{l}\text { Physical physiotherapy } \\
\text { disability service }\end{array}$ & $1(14)$ [554] & 1 (7) [92] & $0.4(4)$ [45] & $1(10)$ [323] & $1(19)[554]$ \\
\hline Podiatrist & $11(60)[958]$ & $18(72)[562]$ & $8(43)$ [389] & $10(57)$ [958] & $12(64)$ [917] \\
\hline Single point of access & $1(6)[83]$ & 2 (7) [83] & $1(7)[41]$ & $1(5)$ [62] & $2(7)[83]$ \\
\hline Speech and language therapy & $17(61)[1,464]$ & $11(40)[385]$ & $16(57)[462]$ & 15 (51) [693] & $19(73)[1,464]$ \\
\hline Tissue viability & $5(28)$ [789] & $5(21)$ [197] & $5(24)[175]$ & $4(24)[526]$ & $6(33)$ [789] \\
\hline Total costs*** & $\begin{array}{r}460(1,879) \\
{[66,681]}\end{array}$ & $\begin{array}{r}762(1,867) \\
{[19,487]}\end{array}$ & $\begin{array}{r}1,724(7,022) \\
{[66,681]}\end{array}$ & $\begin{array}{r}431(1,897) \\
{[66,162]}\end{array}$ & $\begin{array}{r}407(1,066) \\
{[22,398]}\end{array}$ \\
\hline
\end{tabular}

*** Statistically significant difference $\mathrm{p}$-value $<0.001$ based on Kruskal-Wallis (for continuous variables) or Chi-square (for categorical variables) test. 
The mean survival during the follow-up period was 490 (SD: 290) days in the overall sample, 494 (SD: 298) days in the non-psychotic group, 520 (SD: 302) days in the psychotic group, 503 (SD: 299) days in the organic group, and 473 (SD: 276) days in the non-clustered group. The lower survival in residents without mental health conditions is illustrated also in the Kaplan-Meier survival curves (Figure 2). These curves show that the survival probability was very similar in the four groups of mental health up to 16 months (i.e. 480 days) after admission to care home and it dropped faster thereafter in residents without mental health conditions compared to residents with mental health conditions. After adjusting for patient (i.e. age and gender) and care home (i.e. type and size) characteristics, residents with dementia were $30 \%$ (Hazard Ratio: $0.70,95 \% \mathrm{Cl}: 0.63-0.78$ ) less likely to die during the follow-up period compared with residents without mental health conditions (Table 3). Similarly, residents with psychotic conditions and residents with non-psychotic conditions were $25 \%$ (Hazard Ratio: $0.75,95 \% \mathrm{Cl}: 0.58-0.97$ ) and $20 \%$ (Hazard Ratio: $0.80,95 \% \mathrm{Cl}: 0.64-1.00$ ), respectively, less likely to die during the follow-up period compared with residents without mental health conditions.

Figure 2 Survival curves from admission to care home by mental health category

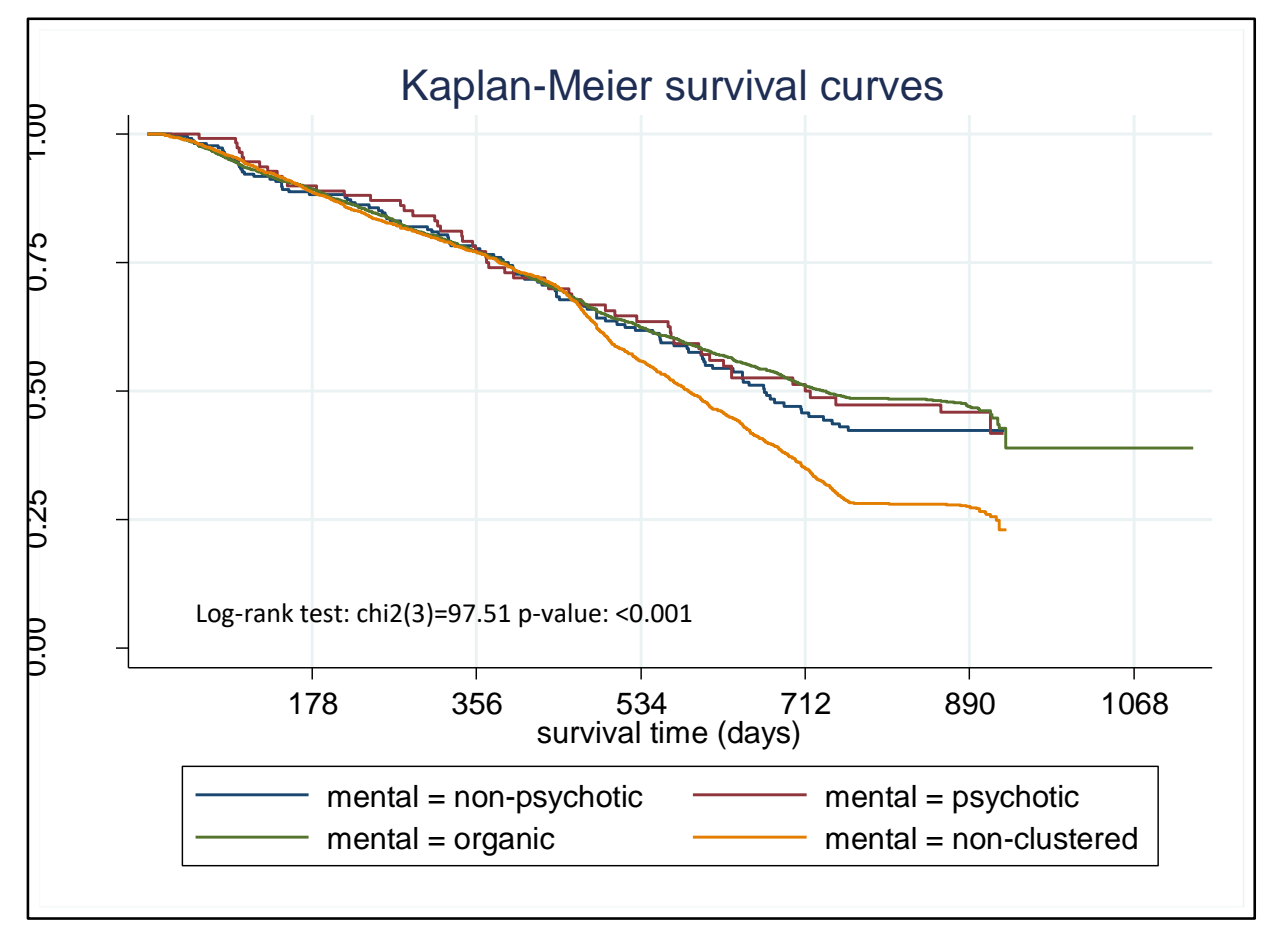

Residents with non-psychotic conditions and residents with psychotic conditions had $62 \%$ (Ratio of Means:1.62, 95\% Cl: 1.13-2.31) and 293\% (Ratio of Means: 3.93, 95\%Cl: 1.68-9.21) higher community care costs respectively, compared to residents without mental health conditions after adjusting for patient (i.e. age and gender) and care home (i.e. type and size) characteristics as well as survival. The 
proportional hazards assumption was tested after fitting the Cox-regression model, which showed that the assumption was not violated.

Table 3 Results from the survival and cost regression analysis

\begin{tabular}{lcc}
\hline Variable & $\begin{array}{c}\text { Survival during follow-up } \\
\text { Hazard ratio (se) [p-value] }\{95 \% \mathrm{Cl}\}\end{array}$ & $\begin{array}{c}\text { 6-month community care costs } \\
\text { Ratio of means (se) [p-value] }\{95 \% \mathrm{Cl}\}\end{array}$ \\
\hline Non-psychotic (reference: non-clustered) & $0.80(0.09)[0.053]\{0.64-1.00\}$ & $1.62(0.29)[0.008]\{1.13-2.31\}$ \\
\hline Psychotic (reference: non-clustered) & $0.75(0.10)[0.028]\{0.58-0.97\}$ & $3.93(1.71)[0.002]\{1.68-9.21\}$ \\
Organic (reference: non-clustered) & $0.70(0.04)[0.000]\{0.63-0.78\}$ & $1.01(0.10)[0.929]\{0.84-1.22\}$ \\
Age (in tens of years) & $1.14(0.04)[0.000]\{1.08-1.20\}$ & $0.83(0.06)[0.005]\{0.73-0.94\}$ \\
Male (reference: female) & $1.25(0.05)[0.000\}(1.15-1.35\}$ & $1.05(0.14)[0.693]\{0.82-1.36\}$ \\
Survival time (months) & -------- & $0.98(0.01)[0.000]\{0.98-0.99\}$ \\
Nursing home (reference: Residential home) & $1.12(0.08)[0.098]\{0.98-1.29\}$ & $0.49(0.07)[0.000]\{0.38-0.65\}$ \\
Number of beds (in tens) & $0.98(0.14)[0.909]\{0.74-1.30\}$ & $1.25(0.52)[0.589]\{0.55-2.83\}$ \\
Constant & ------- & $3,784(2,454)[0.000]\{1,062-13,487\}$ \\
Sample size & 5,739 residents & 5,739 residents clustered in 102 care homes \\
\hline
\end{tabular}

Note: clustered standard errors allow for intra-cluster correlation

\section{Discussion}

The findings of this study show that $6 \%$ of care home residents had mental health conditions and $52 \%$ had dementia. These proportions seem to be similar across all 104 care homes, irrespective of their size. Residents with dementia and residents without mental health conditions were on average older than residents with mental health conditions. Residents without mental health conditions had the lowest survival during follow-up, even after adjusting for patient and care home characteristics. Overall, we found that residents with mental health conditions and dementia contacted emergency multi-disciplinary units, hospital-at-home services, community mental health teams more frequently compared to residents without mental health conditions. On average, the 6-month community care costs of care home residents were $\mathrm{f} 460$. The unadjusted 6 -months community care costs of residents with dementia and those without mental health condition were very similar, £4431 and f407, respectively. However, the unadjusted community care costs of residents with psychotic conditions $(£ 1,724)$ were more than twice the costs of residents with non-psychotic mental health conditions ( $£ 762$ ) and more than four times the costs of residents without mental health conditions ( $£ 407)$. After adjusting for patient and care home characteristics, residents with psychotic conditions and nonpsychotic conditions had three times and 0.5 times higher community care costs, respectively, compared to residents without mental health conditions.

The findings of this study should be considered in light of the limitations. Due to data limitations, we do not have information on informal caregiving and we are also unable to consider co-morbidities of mental and physical health conditions. With regards to the former, literature shows that there is 
substitution between informal care giving and community care use suggesting that the increased availability of community care services is associated with a decline in informal care giving (Pickard, 2012; Saloniki et al., 2019; Stabile et al., 2006). Therefore, these substitution effects should be explored in care homes residents with mental health conditions as they may have more complex needs compared to residents without mental health conditions. With regards to patient comorbidities, differences in co-morbidities in the MHCT clusters can affect differences in costs. There is no evidence in literature investigating differences in co-morbidities of elderly people living in care homes based on the MHCT clusters and their association with costs. However, this can be an extension of this study for future research. Future research can also investigate the use of community care services of the elderly by mental health status not in care homes compared to those in care homes to observe differences in the need for community care services and study the impact of chronic conditions and visitors to care homes on the differences in survival probability of the elderly by MHCT cluster.

Despite these limitations, there are two particular strengths of this study. First, we have a large sample of residents living in care homes, where previous studies were limited due to their small sample size. Secondly, we are able to follow patients for a long time period of two-years to estimate community care use and survival of residents. Our results are likely to be generalizable to England due to several similarities between our estimates and national average estimates. A Care Quality Commission report highlighted that community care services in Oxfordshire were similar and faced the same challenges as in other areas of England (Care Quality Commission, 2017). Moreover, the community services included in our study and their unit costs are similar to the ones reported by the PSSRU (2015). The recorded rate of dementia in people aged over 65 in Oxfordshire is very similar to the average rate of dementia in England (i.e. 4.33\% VS 4.29\%), and care homes in Oxfordshire have higher bed capacity for people over 65 with dementia (Public Health England, 2020). However, the proportion of care home residents with dementia and cognitive impairment found in our study (52\%) was lower compared to the $70 \%$ estimate from the Alzheimer's Society (Kane and Terry, 2015). This may be because the MHCT does not include significant memory problems in the organic cluster. Moreover, an international review found that the prevalence of anxiety disorders in care home residents was likely to be close to $5 \%$ (Creighton et al., 2017). This figure is close to the $4 \%$ prevalence of nonpsychotic conditions found in our study. Regarding psychotic conditions, Oxfordshire had a higher incidence of psychosis in people between 16 and 64 years old compared to the national average (21.0 VS 18.1 per 100,000 people) in 2011 (Public Health England, 2020). Estimates for the elderly population are not available. Furthermore, a previous costing study of care home residents with 
dementia reported similar costs with this study regarding community mental health services (i.e. $£ 50$ per 6 months in 2011/2012 prices) (Romeo et al., 2017).

The estimated community care costs of people in care homes account for approximately $20 \%$ of the total spending per person on healthcare ( $£ 2,350$ in 2015) (Office for National Statistics, 2017). Commissioning $\mathrm{EHCH}$ and other integrated care services for this population should be well designed to adequately include community care services and alternative payment methods should accurately include community care costs. Care home residents with mental health conditions and dementia should additionally be clearly distinguished due to their higher costs compared to those without mental health conditions. Furthermore, studies have shown that the mental health and physical disability needs of residents with dementia were often unmet within care homes (Hancock et al., 2006). Residents with dementia and mental health conditions have a high need of community care services and thus their mental health should be promptly and adequately monitored in care homes. Considering that a third of people with dementia live in care homes and constitute the majority of care home residents, it is essential that care home settings meet the needs of people with dementia (Kane and Terry, 2015) and provide effective interventions to improve quality of life of people with dementia in care homes (Ballard et al., 2018). Our findings show that residents with dementia were about the same age as people without mental health conditions when admitted to care homes and outlived all other groups of residents. This should also be considered when designing efficient capitated payments for this specific population to avoid budget shortfalls. Moreover, the costs of residents with dementia are expected to be higher in case of comorbidity with mental health conditions (Herrmann et al., 2006).

\section{Conclusion}

Our findings indicate that the MHCT provides an informative stratification of care home residents with regards to survival and community care use. There are proportionally more residents in care homes with mental health conditions, who live longer and use more community care services compared to residents without mental health conditions. Such evidence can be helpful to healthcare commissioners to plan, commission, and pay for a large part of the care needed by elderly living in care homes.

\section{References}

Ballard C, Corbett A, Orrell M, Williams, G. Moniz-Cook, E. Romeo, R. Woods, B. Garrod, L. Testad, I. Woodward-Carlton, B. Wenborn, J. Knapp, M. Fossey, J.. (2018) Impact of person-centred care training and person-centred activities on quality of life, agitation, and antipsychotic use in people 
with dementia living in nursing homes: A cluster-randomised controlled trial. PLoS Medicine. 15, DOI: 10.1371/journal.pmed.1002500.

Care Quality Commission (2013) Not just a number: home care inspection programme national overview.

Care Quality Commission (2017) Oxfordshire Local System Review Report. Oxfordshire. Available at: https://www.cqc.org.uk/sites/default/files/20180208_

oxfordshire_local_system_review_report.pdf (accessed 11 September 2020).

Creighton AS, Davison TE and Kissane DW (2017) The correlates of anxiety among older adults in nursing homes and other residential aged care facilities: a systematic review. International Journal of Geriatric Psychiatry 32: 141-154. DOI: 10.1002/gps.4604.

Forder J and Fernandez J. (2011) Length of stay in care homes. Report commissioned by Bupa Care Services. Cantebury.

Gage H, Cheynel J, Williams P, Mitchell, K., Stinton, C., Katz, J., Holland, C., Sheehan, B. (2015) Service utilisation and family support of people with dementia: A cohort study in England. International Journal of Geriatric Psychiatry. 2 DOI: 10.1002/gps.4118.

Godfrey M and Denby T (2004) Depression and older people: towards securing well-being in later life. Policy Press at the University of Bristol

Gordon AL, Franklin M, Bradshaw L, Logan P, Elliott R, Gladman JR. (2014) Health status of UK care home residents: A cohort study. Age and Ageing. 29 DOI: 10.1093/ageing/aft077.

Gustavsson A, Jonsson L, Rapp T, Reynish, E., Ousset, P. J., Andrieu, S., Cantet, C., Winblad, B., Vellas, B., Wimo, A., Ictus Study Group. (2010) Differences in resource use and costs of dementia care between European countries: Baseline data from the ICTUS study. Journal of Nutrition, Health and Aging. 14 DOI: 10.1007/s12603-010-0311-7.

Hancock GA, Woods B, Challis D, Orrell M. (2006) The needs of older people with dementia in residential care. International Journal of Geriatric Psychiatry. 21 DOI: 10.1002/gps.1421.

Herrmann N, Lanctôt KL, Sambrook R, Lesnikova, N., Hebert, R., McCracken, P., Robillard, A., Nguyen, E. (2006) The contribution of neuropsychiatric symptoms to the cost of dementia care. International Journal of Geriatric Psychiatry. 21 DOI: 10.1002/gps.1594.

Kane M and Terry G (2015) Demetia 2015: Aiming higher to transform lives. Alzheimer's Society. https://www.alzheimers.org.uk/download/downloads/id/2700/dementia_2015_aiming_higher _to_transform_lives.pdf

Lafond S, Charlesworth A and Roberts A (2016) A perfect storm: an impossible climate for NHS providers' finances? An analysis of NHS finances and factors associated with financial performance. Health Foundation. London http://www.health.org.uk/publication/perfect-stormimpossible-climate-nhs-providers\%E2\%80\%99-finances

Laig W (2014) Strategic commissioning of long term care fo rolder people: can we get more for less? LaingBuisson. London.

Luengo-Fernandez R, Leal J and Gray AM (2012) UK research expenditure on dementia, heart disease, stroke and cancer: Are levels of spending related to disease burden? European Journal of Neurology. 19 DOI: 10.1111/j.1468-1331.2011.03500.x.

Mental Health Taskforce (2016) The five year forward view for mental health. Available at: https://www.england.nhs.uk/wp-content/uploads/2016/02/Mental-Health-Taskforce-FYFVfinal.pdf. 
Murman DL, Chen Q, Powell MC, Kuo, S. B., Bradley, C. J., Colenda, C. C. (2002) The incremental direct costs associated with behavioral symptoms in AD. Neurology. 59 DOI: 10.1212/01.WNL.0000036904.73393.E4.

National Audit Office (2010) Progress in improving stroke care: report on the findings from our modelling of stroke care provision. London.

NHS England (2014) NHS England " The NHS Five Year Forward View. NHS England.

NHS England (2016a) Developing a capitated payment approach for mental health: detailed guidance.

NHS England (2016b) Developing an episodic payment approach for mental health: detailed guidance.

NHS England (2016c) New care models: vanguards- developing a blueprint for the future of NHS and care services. London. Available at: www.england.nhs.uk/vanguards (accessed 13 January 2020).

NHS England (2016d) The framework for enhanced health in care homes. London.

NHS Improvement (2016) 2017/18 and 2018/19 National Tariff Payment System Annex C: Technical guidance for mental health clusters.

Office for National Statistics (2017) UK Health Accounts: 2015. Available at: https://www.ons.gov.uk/peoplepopulationandcommunity/healthandsocialcare/healthcaresyst em/bulletins/ukhealthaccounts/2015.

Pickard L (2012) Substitution between formal and informal care: A natural experiment in social policy in Britain between 1985 and 2000. Ageing and Society 32: 1147-1175. DOI: 10.1017/S0144686X11000833.

PSSRU (2015) Unit Costs of Health and Social Care 2015. Available at: https://www.pssru.ac.uk/pub/uc/uc2015/full.pdf (accessed 11 September 2020).

Public Health England (2020) Public Health Profiles. Available at: https://fingertips.phe.org.uk/.

Romeo R, Knapp M, Salverda S, Orrell, M., Fossey, J., Ballard, C. (2017) The cost of care homes for people with dementia in England: a modelling approach. International Journal of Geriatric Psychiatry. 32 DOI: 10.1002/gps.4637.

Saloniki E, Nizalova O, Malisauskaite G, Julien Forder (2019) The impact of formal care on informal care for people over 75 in England. Available at: www.pssru.ac.uk (accessed 2 September 2020).

Schaller S, Mauskopf J, Kriza C, Wahlster, P., Kolominsky-Rabas, P. L (2015) The main cost drivers in dementia: A systematic review. International Journal of Geriatric Psychiatry. 30 DOI: 10.1002/gps.4198.

Shah SM, Carey IM, Harris T, DeWilde, S., Cook, D. G. (2013) Mortality in older care home residents in england and wales. Age and Ageing. 42 DOI: 10.1093/ageing/afs174.

Stabile M, Laporte A and Coyte PC (2006) Household responses to public home care programs. Journal of Health Economics 25: 674-701. DOI: 10.1016/j.jhealeco.2005.03.009.

Steventon A and Roberts A (2012) Estimating length of stay in publicly-funded residential and nursing care homes: A retrospective analysis using linked administrative data sets. BMC Health Services Research. 12 DOI: 10.1186/1472-6963-12-377.

Trevithick L, Painter J and Keown P (2015) Mental health clustering and diagnosis in psychiatric inpatients. Psychiatrist. 39 DOI: 10.1192/pb.bp.114.047043.

Tsiachristas A (2015) Payment and economic evaluation of integrated care. Erasmus University Rotterdam. 
Tsiachristas A, Hipple-Walters B, Lemmens KMM, Nieboer, A. P., Rutten-van Molken, M. P. (2011) Towards integrated care for chronic conditions: Dutch policy developments to overcome the (financial) barriers. Health Policy. 101 DOI: 10.1016/j.healthpol.2010.10.013.

Tsiachristas A, Dikkers C, Boland MRS, Rutten-van Molken, M. P. (2013) Exploring payment schemes used to promote integrated chronic care in Europe. Health Policy. 113 DOI: 10.1016/j.healthpol.2013.07.007. 


\section{Appendix}

Box 1 Community care services included in the data set, units of measurement, and unit cost

general ward in community hospital (days), $£ 317.59$

mental health ward in community hospital (days), $£ 448.94$

community matron (visits), $£ 132.45$

community therapy service (visits), £263.37

district nurse (visits), $£ 41.32$

emergency multidisciplinary unit (visits), £361.81

hospital-at-home (visits), $£ 160.03$

minor injury unit, (visits), $£ 60.04$

musculoskeletal service (visits), $£ 56.11$

out-of-hours service (visits), $£ 83.85$

memory clinic (visits), £203.3

community mental health team (visits), $£ 191.27$

physical physiotherapy disability service (visits), $£ 92.38$

podiatry (visits), $£ 41.66$

single point of access (visits), $£ 41.32$

speech and language therapy (visits), $£ 77.04$

tissue viability (visits), $£ 87.66$ 